\title{
Incertezas Associadas ao Uso do Sensoriamento Remoto na Estimativa do Balanço Hídrico
}

\author{
Uncertainties Related to the Use of Remote Sensing in the Water Balance Estimation
}

\section{Luiza Souza de Paula @ \& \& Guilherme Garcia de Oliveira}

Universidade Federal do Rio Grande do Sul, Centro Estadual de Pesquisas em Sensoriamento Remoto e Meteorologia, Porto Alegre, RS, Brasil

E-mails: luizasouza.dp@gmail.com; g.g.oliveira10@gmail.com

\section{Resumo}

A quantificação dos recursos hídricos disponíveis é fundamental para o seu gerenciamento adequado e para a sustentação da qualidade de vida. Convencionalmente, as variáveis hidrológicas são estabelecidas por medições in situ, no entanto há escassez desses dados, tornando o Sensoriamento Remoto (SR) uma alternativa atraente. O objetivo deste trabalho é obter o balanço hídrico em bacias hidrográficas a partir de fontes de dados in situ e dados de SR de nível orbital, identificar os modelos com melhores resultados, as principais fontes de incertezas e o efeito de escala espacial e temporal. Para isso, foram selecionadas 10 bacias hidrográficas no estado do Rio Grande do Sul. Coletou-se dados de estações meteorológicas, pluviométricas e fluviométricas e de SR sobre precipitação (P), evapotranspiração (ET), vazão (Q) e armazenamento de água terrestre (S). Calculou-se o balanço hídrico a partir destes dados, mesclando ambas as fontes. Os produtos de SR utilizados foram: Tropical Rainfall Measuring Mission (TRMM), Global Amsterdam Evaporation Land Model (GLEAM) e Gravity Recovery and Climate Experiment (GRACE). Na estimativa de vazão pela equação simples constatou-se que a utilização de ET via SR é uma alternativa viável quando há escassez de dados provenientes de estações meteorológicas. Por sua vez, o uso de dados de armazenamento de água por SR na equação de balanço hídrico não resultou em uma quantificação precisa das vazões fluviais, ainda que, em um período suficientemente longo de análise, tenha se constatado uma redução do erro no balanço de água em bacias maiores. As estimativas de $\mathrm{S}$ calculadas por fontes mistas de dados demonstraram resultados excelentes. Concluiu-se que é possível estimar o balanço hídrico em bacias hidrográficas a partir de dados obtidos por SR, no entanto a precisão destas estimativas é resultado de diversos fatores: localização, tamanho da bacia, época do ano e escala temporal de análise.

Palavras-chave: bacias hidrográficas; recursos hídricos; dados TRMM

\begin{abstract}
Quantification of available hydric resources is essential to its proper management and sustained quality of life. Usually, hydrological variables are determined by in situ measurements; however, shortage of this kind of data makes utilizing remote sensing (RS) a good alternative. The scope of the present study is to obtain the water balance for different watersheds from both in situ data and orbital RS data, to determine the best results models, to identify the main sources of uncertainties and to analyze the spatial and temporal scale effects. Therefore, ten watersheds in the Rio Grande do Sul state with available field data were selected. Precipitation (P), evapotranspiration (ET), runoff $(\mathrm{Q})$, and water storage $(\mathrm{S})$ data were collected from meteorological, pluviometric and fluviometric stations as well as from remote sensing. Hence, water balance was calculated from this data merging both sources of data. The remote sensing products used were: Tropical Rainfall Measuring Mission (TRMM), Global Amsterdam Evaporation Land Model (GLEAM) and Gravity Recovery and Climate Experiment (GRACE). The Q estimate from the simplified equation found that the use of ET remotely sensed data is a viable alternative when there is a lack of data from meteorological stations. The use of S data from RS in the equation of water balance was not able to precisely quantify the river flows. However, in a long period of analysis the use of this kind of data lowered errors in the water balance calculation, especially in larger basins. The S estimates calculated from mixed data sources showed excellent results. This work concluded that it is possible to estimate the water balance in hydrographic basins from RS data; nonetheless, the estimates' accuracy is dependant on various factors such as localization, drainage area, season, temporal scale of analysis.
\end{abstract}

Keywords: watersheds; water resources; TRMM data 


\section{Introdução}

Com o cenário atual, em que a água potável está se tornando cada vez mais escassa, é de suma importância o estudo da disponibilidade hídrica (D’angiotella et al., 2005). A gestão de recursos hídricos tem por objetivo atender em níveis sustentáveis as demandas econômicas, sociais e ambientais por água, possibilitando a convivência de seus usos atuais e futuros (Soares et al., 2010). Os problemas associados à falta de gerenciamento em bacias urbanas e rurais englobam falta do recurso para o abastecimento, precariedade no saneamento, assoreamento dos cursos d'água e a contaminação por agrotóxicos e fertilizantes (Porto \& Ferreira, 2012).

Para obtenção do total de água disponível é necessário conhecer os fluxos de precipitação $(\mathrm{P})$, evapotranspiração (ET) e escoamento(Q) (Sheffield et al., 2009). A contabilização das entradas e saídas deste sistema fornece o armazenamento de água terrestre (S), ou seja, a água armazenada sobre e abaixo da superfície (Tang et al., 2010). Esta contabilização da água na terra é denominada de balanço hídrico (Sentelhas et al., 1999).

Os métodos usualmente aplicados para estimar o armazenamento de água em bacias hidrográficas incluem dados provenientes de observações in situ, modelagem hidrológica, balanço hídrico e técnicas de Sensoriamento Remoto (SR). A sua determinação direta é difícil devido a dados in situ insuficientes para caracterizar a variabilidade espaço-temporal das reservas hidrológicas e dos fluxos envolvidos no processo. No entanto, métodos alternativos que usam novos conjuntos de dados provenientes de SR mostram um grande potencial para melhorar a estimativa da dinâmica do armazenamento de água sazonal e interanual (Troch et al., 2007). Ao mesmo tempo, levanta novos desafios: qual a significância das discrepâncias entre diferentes fontes de dados? Qual a exatidão e a consistência de cada fonte e as incertezas à estimativa final? Além disso, em muitos casos, as estimativas de componentes do balanço hídrico a partir de diferentes fontes não fecham o armazenamento de água terrestre, ou seja, a restrição física básica do balanço de massa de água não é satisfeita (Pan et al., 2012).

Nesta perspectiva, cita-se os seguintes estudos que incorporaram SR na estimativa de componentes do ciclo hidrológico: Bastiaanssen \& Chandrapala (2003); Mccabe et al. (2008); Sheffield et al. (2009); Gao et al. (2010); Tang et al. (2010); Thomas et al. (2014); Paiva \& Ruhoff (2017); Moreira \& Ruhoff (2017); Moreira et al. (2018). De modo geral, esses estudos apontam para uma crescente utilização dos dados de Sensoriamento Remoto para quantificações em hidrologia, e também indicam uma redução das incertezas e erros associados a esse tipo de produto, ainda que a grande maioria aborde os componentes do ciclo hidrológico de forma isolada e, em alguns casos, por meio de uma validação pontual dos dados.

Nesse contexto, o objetivo deste trabalho é obter o balanço hídrico de forma integrada em bacias hidrográficas, a partir de fontes de dados in situ e de dados de SR das variáveis do ciclo hidrológico. Por conseguinte, pretende-se identificar os modelos de balanço hídrico com melhores resultados, ressaltar as principais fontes de incertezas e analisar o efeito de escala espacial e temporal sobre a precisão da quantificação dos volumes de água.

\section{Materiais e Métodos}

\section{1 Área de Estudo}

O presente trabalho foi realizado em dez bacias distribuídas nas três regiões hidrográficas $(\mathrm{RH})$ do Rio Grande do Sul (RS), Brasil. Para seleção das áreas de estudo analisou-se a disponibilidade de dados de escoamento in situ de estações fluviométricas, assim como sua respectiva área de drenagem e localização, visando incorporar bacias de diferentes tamanhos e distribuídas espacialmente sobre o RS.

A Figura 1 apresenta as estações fluviométricas utilizadas para extração das bacias, sua área de drenagem, e a localização das bacias hidrográficas de estudo. Vale destacar que B09 e B02 constituem-se em sub-bacias de $\mathrm{B} 10$. Além disso, uma pequena parte da área de drenagem da bacia B10, pertencente à Região Hidrográfica do Rio Uruguai, localizada em território argentino, não sendo possível a coleta de dados in situ nesta parcela.

\subsection{Coleta de Dados}

Foram obtidos dados in situ de $\mathrm{P}$ (estações pluviométricas), ET (estações meteorológicas) e Q (estações fluviométricas), além de dados estimados por SR de P, ET e S. O período de análise foi entre 2000 e 2018, em função da disponibilidade de dados de SR. As séries foram discretizadas no intervalo de tempo mensal para o cálculo do balanço hídrico.

Os dados de P observada in situ foram obtidos do sistema Hidroweb da Agência Nacional de Águas (ANA) para os estados do Rio Grande do Sul e Santa Catarina, das estações pluviométricas com séries disponíveis para o período 2000-2018, em um total de 450 estações. Foi realizada uma interpolação dos valores de $\mathrm{P}$ a partir do método do inverso do quadrado da distância para uma malha de pontos distribuídos com equidistância de $20 \mathrm{~km}$. Após atribuído o valor de $\mathrm{P}$ mensal para cada ponto, foi realizada uma média dos valores dos pontos em cada bacia de estudo, para cada mês da série temporal. 


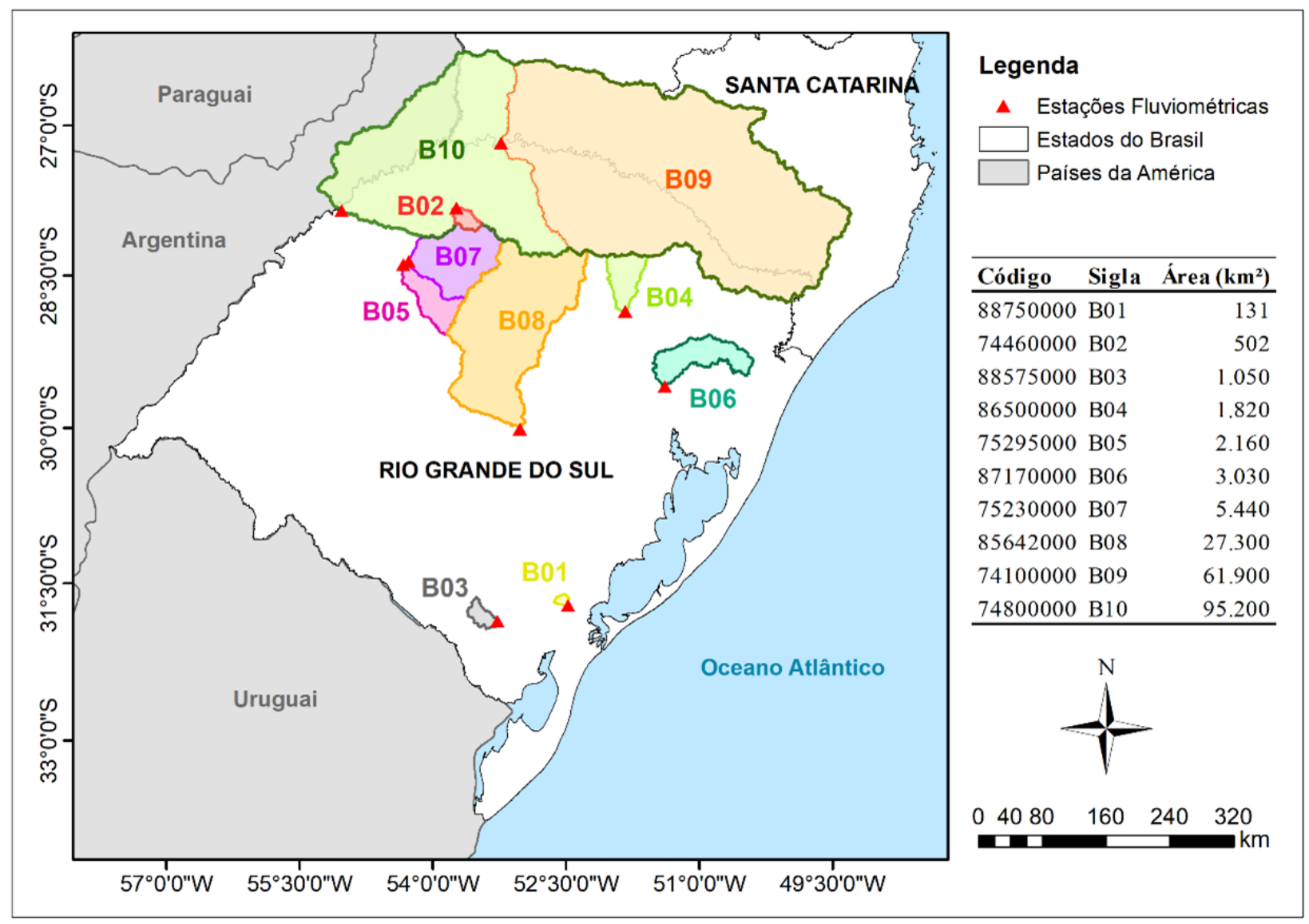

Figura 1 Bacias de estudo com suas estações fluviométricas e áreas de drenagem.

Os dados de ET mensal foram obtidos do Banco de Dados Meteorológicos para Ensino e Pesquisa (BDMEP) do Instituto Nacional de Meteorologia (INMET). Devido à baixa disponibilidade destes dados, com 22 estações distribuídas pelo RS e SC, procedeu-se da seguinte forma: para as bacias com mais de uma estação disponível, foi utilizada a média dos valores; para as bacias menores, sem estações, utilizou-se os dados da estação mais próxima.

Os dados de escoamento foram obtidos do sistema Hidroweb da ANA das 10 estações previamente selecionadas. Optou-se pelo uso de séries já consistidas, no mesmo período dos dados de P e ET. Na Figura 2 são espacializadas todas as estações com séries disponíveis de precipitação, evapotranspiração e vazão.

Para obtenção dos dados de P por SR, optou-se pelas imagens do satélite Tropical Rainfall Measuring Mission (TRMM). O produto utilizado foi o TRMM 3B43, uma estimativa de P com resolução espacial de $0,25^{\circ}$ (TRMM, 2011). Os dados de $\mathrm{S}$ foram obtidos da missão Gravity Recovery and Climate Experiment (GRACE). O produto utilizado foi o "JPL TELLUS GRACE Level-3 Monthly
LAND Water-Equivalent-Thickness Surface-Mass Anomaly Release 6", com resolução espacial de $1^{\circ}$. Para estimativa de ET por SR selecionou-se o produto mensal Global Amsterdam Evaporation Land Model (GLEAM) (Martens et al., 2017). A resolução espacial do produto GLEAM é de $0,25^{\circ}$. Todos os produtos foram processados e discretizados, de modo a se calcular o valor mensal de P, ET e S em cada bacia de estudo, entre 2000-2018.

\subsection{Balanço Hídrico}

O balanço hídrico foi obtido por três equações. Primeiramente, utilizou-se uma equação de balanço hídrico mais simples (Equação 1) para análises do escoamento no intervalo anual, utilizando quatro combinações de dados observados in situ e estimados por SR (Tabela 1).

Empregou-se também uma equação do balanço hídrico completa (Equação 2), isolando-se o escoamento para períodos mensais, anuais e para a série histórica completa (2000 a 2018), o que resultou em mais sete combinações de dados (Tabela 2). 
Para obtenção do S aplicou-se a Equação 3, na qual foram realizadas as quatro combinações possíveis de dados (Tabela 3). Para análise do armazenamento utilizou-se como referência o valor de S0, o qual serviu como base para o cálculo dos índices de desempenho. Neste último caso, as equações foram utilizadas para intervalos mensais, anuais e históricos.

$$
\begin{gathered}
Q=P-E T \\
Q=P-E T-S \\
\Delta S=P-E T-Q
\end{gathered}
$$

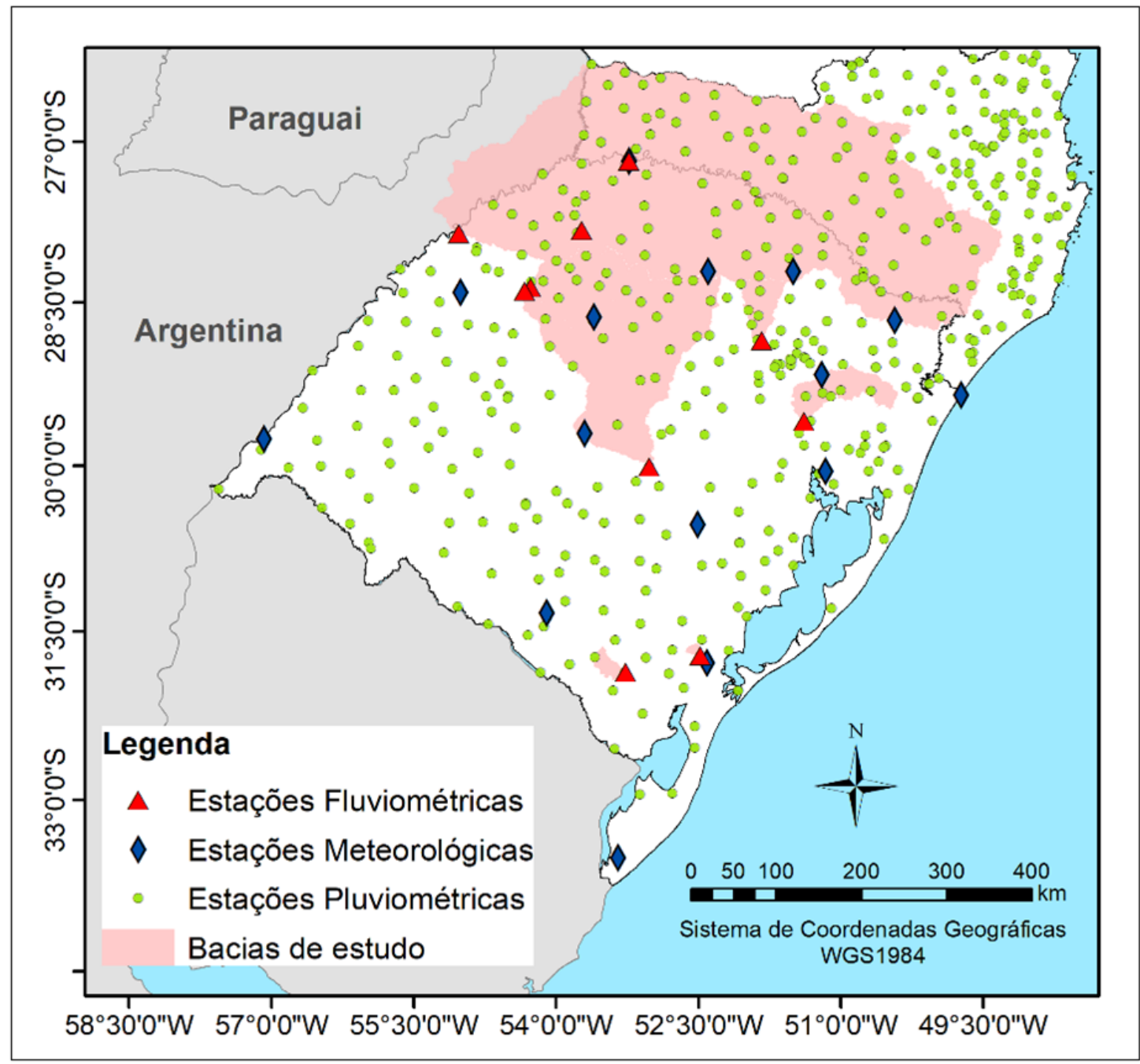

Figura 2 Estações utilizadas para extração de dados in situ.

Tabela 1 Combinações de dados para o cálculo das vazões (Q) pela equação simplificada do balanço hídrico.

\begin{tabular}{ccc}
\hline \multirow{2}{*}{ Cenários de $\mathbf{Q}$} & \multicolumn{2}{c}{ Fonte de dados } \\
\cline { 2 - 4 } & Precipitação (P) & Evapotranspiração (ET) \\
\hline Q1 & In situ & In situ \\
Q2 & Sensoriamento Remoto & In situ \\
Q3 & In situ & Sensoriamento Remoto \\
\hline
\end{tabular}


Tabela 2 Combinações de dados para o cálculo das vazões (Q) pela equação completa do balanço hídrico.

\begin{tabular}{cccc}
\hline \multirow{2}{*}{ Cenários de $\mathbf{Q}$} & \multicolumn{3}{c}{ Fonte de dados } \\
\cline { 2 - 4 } & Precipitação (P) & Evapotranspiração (ET) & Armazenamento de água (S) \\
\hline Q4 & In situ & In situ & Sensoriamento Remoto \\
Q6 & Sensoriamento Remoto & In situ & In situ \\
Q7 & In situ & Sensoriamento Remoto & In situ \\
Q8 & Sensoriamento Remoto & Sensoriamento Remoto & In situ \\
Q9 & Sensoriamento Remoto & In situ & Sensoriamento Remoto \\
Q10 & In situ & Sensoriamento Remoto & Sensoriamento Remoto \\
\hline
\end{tabular}

Tabela 3 Combinações de dados para o cálculo do armazenamento de água (S) pela equação completa do balanço hídrico.

\begin{tabular}{cccc}
\hline \multirow{2}{*}{ Cenários de $\mathbf{c}$} & \multicolumn{1}{c}{ Fonte de dados } & Vazão (Q) \\
\cline { 2 - 4 } & Precipitação (P) & Evapotranspiração (ET) & In situ \\
S0 & In situ & In situ & In situ \\
S2 & Sensoriamento Remoto & In situ & In situ \\
S3 & In situ & Sensoriamento Remoto & In situ \\
\hline
\end{tabular}

\subsection{Análise Estatística}

A partir dos cálculos de Q e S, extraiu-se uma série de indicadores para análise das incertezas associadas a aplicação de dados provenientes de SR na equação do balanço hídrico: Erro Absoluto Médio (EA) - Equação 4; Raiz do Erro Quadrático Médio (REQM) - Equação 5; Índice de Concordância (d) - Equação 6; Coeficiente de Correlação Linear de Pearson (r) - Equação 7; Coeficiente de Nash-Sutcliffe (E) - Equação 8; Diferença da altura de escoamento total - Equação 9.

$$
\begin{gathered}
E A=\frac{1}{n} \sum\left|X_{e s t}-X_{o b s}\right| \\
R E Q M=\sqrt{\frac{1}{n} \sum\left(X_{e s t}-X_{o b s}\right)^{2}} \\
d=1-\left[\frac{\sum\left(X_{e s t}-X_{o b s}\right)^{2}}{\sum\left(\left|X_{e s t}-\overline{X_{o b s}}\right|+\left|X_{o b s}-\overline{X_{o b s}}\right|\right)^{2}}\right] \\
r=\frac{\sum\left(X_{e s t}-\overline{X_{e s t}}\right) \cdot\left(X_{o b s}-\overline{X_{o b s}}\right)}{\sqrt{\sum\left(X_{e s t}-\overline{X_{e s t}}\right)^{2} \cdot \sum\left(X_{o b s}-\overline{X_{o b s}}\right)^{2}}}
\end{gathered}
$$

$$
\begin{gathered}
E=1-\left[\frac{\sum\left(X_{o b s}-X_{e s t}\right)^{2}}{\sum\left(X_{o b s}-\overline{X_{o b s}}\right)^{2}}\right] \\
\neq Q t=\sum X_{e s t}-\sum X_{o b s}
\end{gathered}
$$

Em que: $\mathrm{n}=$ número de meses analisados; $\mathrm{X}_{\text {est }}$ = variável estimada; $\mathrm{X}_{\mathrm{obs}}=$ variável observada; $\overline{X_{\text {obs }}} \stackrel{\text { est }}{=}$ média dos valores observados; $\overline{X_{\text {est }}}$. $=$ média dos valores estimados.

\section{Resultados e Discussão}

\subsection{Vazões Calculadas pela Equação Simples}

Os gráficos de dispersão para as vazões anuais calculadas com a equação simples estão expressos na Figura 3. Para Q0 e Q1 os menores valores de Q foram subestimados, apresentando inclusive valores negativos, ou seja, maior do que a $\mathrm{P}$, e os maiores valores foram superestimados. Esta tendência é confirmada pelas equações da reta, ambas foram muito similares e apresentaram coeficientes angulares mais baixos, 0,55 para Q0 e 0,53 para Q1. Q2 e Q3 apresentam seus dados muito mais próximos da linha ideal, sendo mais precisos para valores mais baixos de $\mathrm{Q}$ e superestimando os valores mais altos, principalmente Q3. 


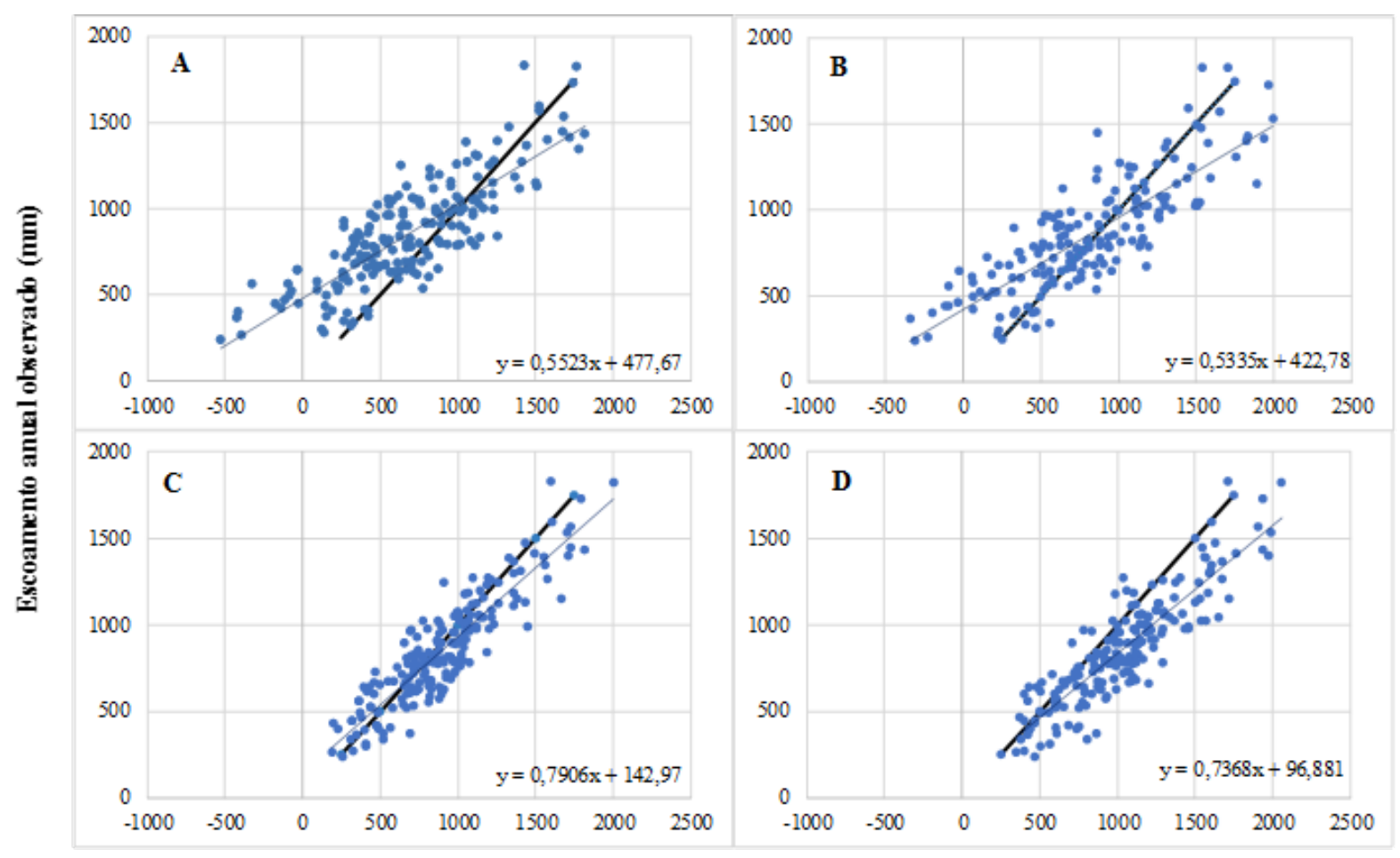

Escoamento anual calculado (mm)

Figura 3 Gráficos de dispersão do escoamento anual calculado pela equação simplificada do balanço hídrico em relação ao observado em 10 estações fluviométricas localizadas no RS; A. Q0; B. Q1; C. Q2; D. Q3.

O cenário Q2 obteve o melhor desempenho com uma menor dispersão dos dados. Nesta equação, utilizouse a $\mathrm{P}$ in situ e a ET via SR, o que nos permite concluir que são as fontes com menores incertezas nesta análise, o que é plenamente compreensível em razão da abundância de dados de $\mathrm{P}$ medidos em campo, em contraponto com a ausência de dados de ET. Q3 teve uma superioridade de predição se comparado a $\mathrm{Q} 0$, sendo que o primeiro utilizou apenas como fonte de dados o SR e o segundo apenas dados in situ.

A partir das vazões calculadas foi possível extrair indicadores de desempenho e identificar incertezas associadas a esta variável, por meio da comparação com os dados medidos pelas estações fluviométricas. A Tabela 4 mostra a análise estatística de Q0, Q1, Q2 e Q3, considerando as 10 bacias em conjunto. Identificase um ótimo desempenho dos índices de concordância e coeficientes de correlação, em que as médias ficaram todas acima de 0,8 . No que tange ao erro absoluto médio também foram muito satisfatórios, destaca-se Q2 com menores valores de média. Em geral, Q2 e Q3 demonstraram valores mais baixos e com menor amplitude, seguido de Q1 e com pior desempenho Q0.
Ao analisar os índices de concordância e coeficiente de correlação obtidos entre as bacias, apenas a bacia B01 apresentou uma leve redução do coeficiente de correlação frente as demais, 0,65 para Q0 e 0,68 para Q1. O que demonstra certa imprecisão associada aos dados de ET in situ para esta bacia. Os índices de concordância, ficaram todos acima de 0,7 . O que comprova o bom desempenho das vazões calculadas pelas diferentes fontes de dados.

$\mathrm{Na}$ bacia B09 e B10 o erro absoluto médio diminui para Q0 e Q2, e aumenta para Q1 e Q3, ou seja, a precisão dos dados de $\mathrm{P}$ in situ é maior do que via SR para grandes áreas, visto que existe grande número de estações meteorológicas no interior destas bacias. Logo, nestes casos, a fonte dos dados de ET não atua significantemente na exatidão da Q calculada.

Outro destaque é a bacia B03, em que Q0 e Q1 apresentaram erros e incertezas maiores do que nas demais bacias. Este comportamento pode indicar problemas com os dados de ET in situ, visto que a estação meteorológica da qual foi obtida esta variável se encontrava distante do local de análise, em função do tamanho da bacia e da ausência de estações meteorológicas. 
Tabela 4 Análise estatística das vazões calculadas pela equação simplificada do balanço hídrico anual - valores mínimos, médios e máximos, nas bacias analisadas, por índice de desempenho.

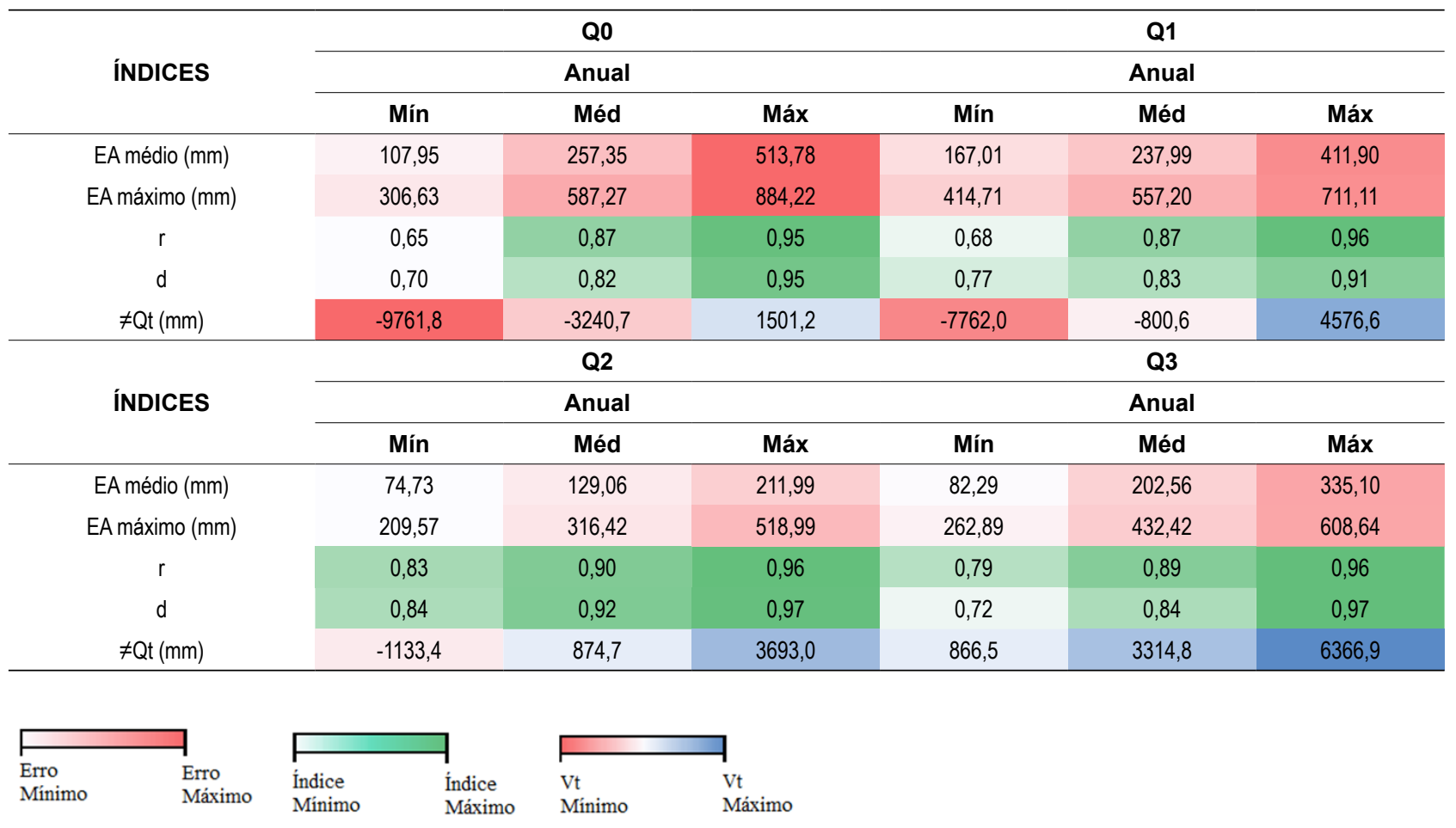

No panorama geral, não foi verificado um efeito de escala espacial muito visível, apenas para Q0 que se identificou uma redução dos erros absolutos médios para as bacias de maiores dimensões (B08, B09 e B10). O que pode estar associado ao fato destas bacias possuírem mais estações meteorológicas no seu interior e consequentemente maior precisão dos dados in situ.

A respeito da diferença da altura de escoamento total do período de análise (2000 a 2018), Q0 e Q1 subestimaram os valores de $Q$ na maioria das bacias, no entanto para B09 e B10 (bacias de maiores áreas) os valores ficam acima do observado. Em contraponto, Q2 e Q3 superestimam os valores na maioria das bacias, sendo Q3 com uma amplitude maior de diferença histórica. As menores diferenças foram evidenciadas em Q2.

Com isso, conclui-se que a tendência da diferença histórica é ditada pela fonte de obtenção dos dados de ET, de maneira que a equação que utilizou dados de ET in situ subestimou os valores, com exceção das maiores bacias, e a que utilizou ET via SR superestimou a Q.

Q2 apresentou melhor performance ao analisar os indicadores, o que indica que a utilização de ET via SR diminui as imprecisões se comparado com a ET medida in situ, visto que há uma baixa disponibilidade de dados. Esperava-se que Q0 apresentasse melhor predição, haja vista que os dados de ambas as variáveis da equação foram extraídos em campo, no entanto obteve índices abaixo dos demais, ou seja, as imprecisões das medições in situ combinadas amplificaram o erro. Uma melhor alternativa é agregar dados de sensoriamento em condições de baixa disponibilidade de dados observacionais.

\subsection{Vazões Calculadas pela Equação Completa}

Os gráficos de dispersão dos dados anuais de Q calculada pela equação completa versus $\mathrm{Q}$ observada podem ser vistos na Figura 4. As vazões calculadas Q4, Q8, Q9 e Q10 obtiveram uma grande dispersão dos dados e coeficientes angulares baixos, em que os valores baixos de Q são subestimados e os altos são superestimados. Esta tendência está atrelada principalmente aos dados de armazenamento de água proveniente da missão GRACE.

As vazões Q5, Q6 e Q7 obtiveram um desempenho muito bom, em que os dados se dispõem próximos à reta ideal. No entanto, esses três modelos possuem melhor predição dos valores baixos de $Q$ e tendem a superestimar os valores extremos altos. Q5 teve a melhor performance, os dados estão próximos do ideal com coeficiente angular de 0,81 . Desta forma, conclui-se que a menor fonte de incertezas proveniente de SR na equação do balanço hídrico em uma escala anual é a P, seguido da ET e da combinação de ambas. 


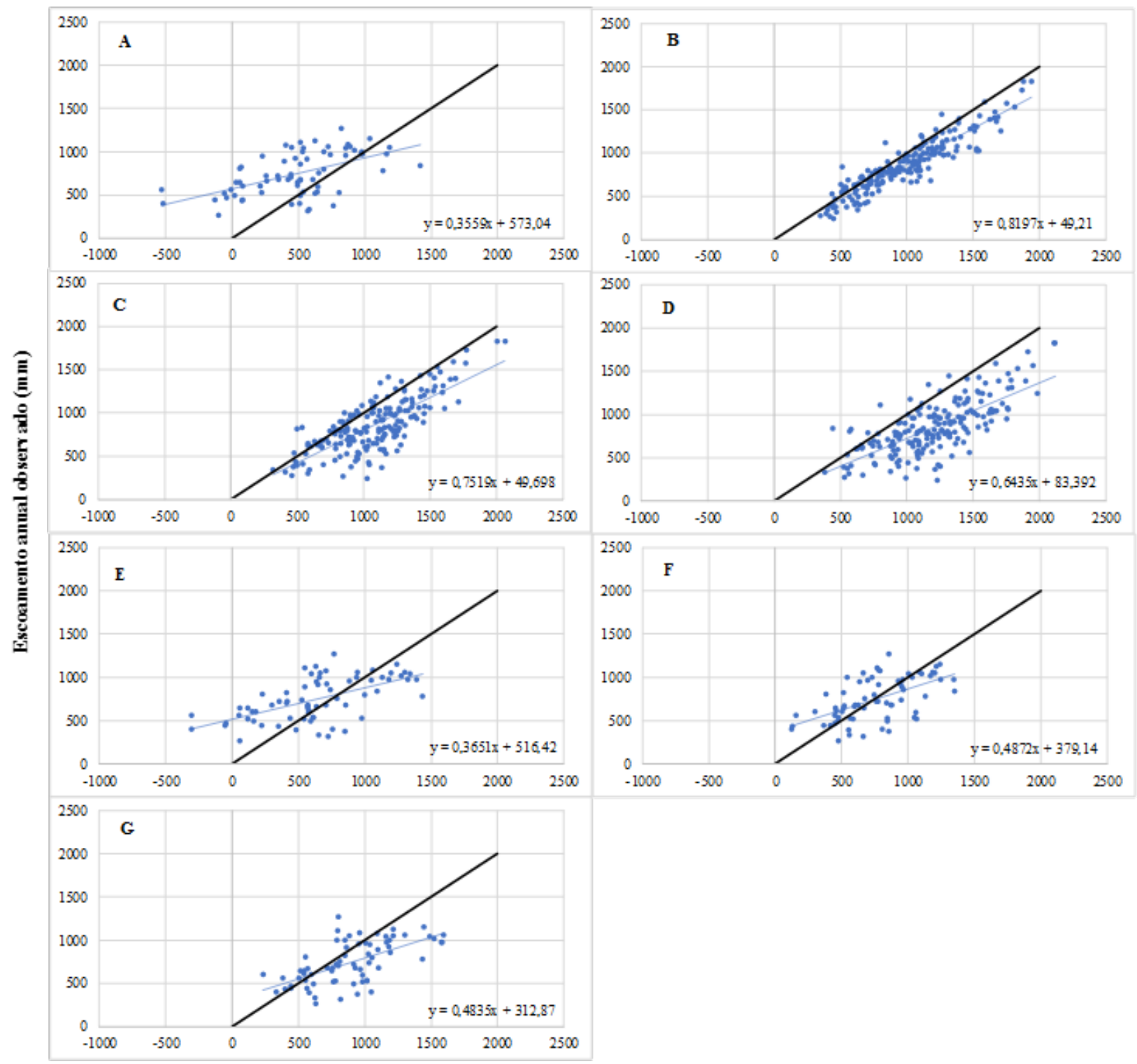

Escoam ento anual calculado $(\mathrm{mm})$

Figura 4 Gráficos de dispersão do escoamento anual calculado pela equação completa do balanço hídrico em relação ao observado nas estações fluviométricas; A. Q4; B. Q5; C. Q6; D. Q7; E. Q8; F. Q9; G. Q10.

A Tabela 5 traz os valores mínimos, médios e máximos dos índices de desempenho. Em relação aos valores do coeficiente de correlação mensal, os resultados foram de moderado a bom. Para o coeficiente de correlação anual os dados apresentaram maior amplitude de valores, demonstrando desde performance ruim a muito boa em determinadas áreas de estudo. As vazões calculadas Q5, Q6 e Q7 obtiveram melhores coeficientes de correlação se comparadas às demais.Moreira \& Ruhoff (2017) ao estimarem o balanço hídrico na América do Sul a partir de dados de SR, obtiveram valores de variação do $\mathrm{S}$ calculado consistentes quando comparados aos dados GRACE. No entanto, os valores mais significativos estavam associados as maiores bacias e localizados mais ao norte da América do Sul (com climas equatorial e tropical), enquanto menores correlações foram encontradas em pequenas bacias na região sul do Brasil (tipicamente em clima subtropical). Observaram que os melhores resultados foram identificados para bacias com áreas maiores e com sazonalidade de $\mathrm{P}$ bem definida, o que pode explicar a baixa capacidade de estimativa do $\mathrm{S}$ pelo satélite GRACE no presente estudo. 
Tabela 5 Análise estatística das vazões calculadas pela equação completa do balanço hídrico, mensal e anual - valores mínimos, médios e máximos, nas bacias analisadas, por índice de desempenho.

\begin{tabular}{|c|c|c|c|c|c|c|c|c|c|c|c|c|}
\hline \multirow{3}{*}{ ÍNDICES } & \multicolumn{3}{|c|}{ Q4 } & \multicolumn{3}{|c|}{ Q5 } & \multicolumn{3}{|c|}{ Q6 } & \multicolumn{3}{|c|}{ Q7 } \\
\hline & \multicolumn{3}{|c|}{ Mensal } & \multicolumn{3}{|c|}{ Mensal } & \multicolumn{3}{|c|}{ Mensal } & \multicolumn{3}{|c|}{ Mensal } \\
\hline & Mín & Méd & Máx & Mín & Méd & Máx & Mín & Méd & Máx & Mín & Méd & Máx \\
\hline EA médio (mm) & 50,55 & 60,44 & 75,20 & 20,56 & 25,34 & 31,29 & 19,66 & 27,81 & 40,21 & 28,04 & 41,95 & 53,26 \\
\hline EA máximo $(\mathrm{mm})$ & 159,34 & 220,88 & 290,35 & 83,85 & 149,80 & 261,35 & 74,11 & 106,33 & 153,93 & 110,64 & 164,87 & 285,15 \\
\hline REQM (mm) & 64,82 & 75,69 & 93,14 & 26,71 & 34,25 & 43,35 & 23,89 & 33,42 & 47,57 & 34,61 & 51,03 & 63,89 \\
\hline$r$ & 0,45 & 0,56 & 0,69 & 0,71 & 0,86 & 0,92 & 0,83 & 0,89 & 0,93 & 0,59 & 0,77 & 0,87 \\
\hline$d$ & 0,56 & 0,67 & 0,79 & 0,82 & 0,91 & 0,95 & 0,86 & 0,91 & 0,95 & 0,69 & 0,82 & 0,89 \\
\hline$E$ & $-2,95$ & $-1,10$ & 0,14 & 0,15 & 0,59 & 0,80 & 0,38 & 0,62 & 0,81 & $-0,64$ & 0,11 & 0,56 \\
\hline \multirow{2}{*}{ ÍNDICES } & \multicolumn{3}{|c|}{ Anual } & \multicolumn{3}{|c|}{ Anual } & \multicolumn{3}{|c|}{ Anual } & \multicolumn{3}{|c|}{ Anual } \\
\hline & Mín & Méd & Máx & Mín & Méd & Máx & Mín & Méd & Máx & Mín & Méd & Máx \\
\hline EA médio $(\mathrm{mm})$ & 132,83 & 340,20 & 661,03 & 95,35 & 149,81 & 235,41 & 82,49 & 242,53 & 454,13 & 157,89 & 363,68 & 559,38 \\
\hline EA máximo $(\mathrm{mm})$ & 351,51 & 599,00 & 1092,18 & 240,23 & 379,74 & 522,03 & 293,86 & 519,71 & 783,01 & 364,54 & 701,14 & 992,42 \\
\hline$r$ & $-0,07$ & 0,48 & 0,84 & 0,87 & 0,92 & 0,97 & 0,55 & 0,83 & 0,94 & 0,42 & 0,74 & 0,83 \\
\hline$d$ & 0,20 & 0,53 & 0,79 & 0,80 & 0,90 & 0,96 & 0,60 & 0,77 & 0,93 & 0,44 & 0,65 & 0,85 \\
\hline$\neq \mathrm{Qt}$ & $-8281,7$ & $-4021,4$ & $-350,0$ & 385,2 & 2440,1 & 4367,0 & $-627,3$ & 4115,4 & 8628,5 & 2121,1 & 6555,5 & 10628,3 \\
\hline \multirow{3}{*}{ ÍNDICES } & \multicolumn{3}{|c|}{ Q8 } & \multicolumn{3}{|c|}{ Q9 } & \multicolumn{3}{|c|}{ Q10 } & & & \\
\hline & \multicolumn{3}{|c|}{ Mensal } & \multicolumn{3}{|c|}{ Mensal } & \multicolumn{3}{|c|}{ Mensal } & & & \\
\hline & Mín & Méd & Máx & Mín & Méd & Máx & Mín & Méd & Máx & & & \\
\hline EA médio $(\mathrm{mm})$ & 50,81 & 61,80 & 73,93 & 42,37 & 53,27 & 66,09 & 45,96 & 56,56 & 67,94 & & & \\
\hline EA máximo $(\mathrm{mm})$ & 151,95 & 213,89 & 289,74 & 134,39 & 207,65 & 295,80 & 156,10 & 219,60 & 291,21 & & & \\
\hline REQM (mm) & 62,23 & 76,97 & 92,36 & 53,49 & 67,49 & 83,56 & 55,92 & 70,90 & 85,32 & & & \\
\hline r & 0,40 & 0,53 & 0,68 & 0,38 & 0,53 & 0,68 & 0,33 & 0,50 & 0,65 & & & \\
\hline$d$ & 0,55 & 0,67 & 0,79 & 0,58 & 0,70 & 0,82 & 0,55 & 0,68 & 0,80 & & & \\
\hline$E$ & $-2,88$ & $-1,17$ & 0,05 & $-2,18$ & $-0,71$ & 0,31 & $-2,31$ & $-0,87$ & 0,18 & & & \\
\hline \multirow{2}{*}{ ÍNDICES } & \multicolumn{3}{|c|}{ Anual } & \multicolumn{3}{|c|}{ Anual } & \multicolumn{3}{|c|}{ Anual } & & & \\
\hline & Mín & Méd & Máx & Mín & Méd & Máx & Mín & Méd & Máx & & & \\
\hline EA médio (mm) & 171,67 & 283,93 & 485,04 & 119,32 & 200,67 & 245,56 & 161,54 & 233,21 & 395,54 & & & \\
\hline EA máximo $(\mathrm{mm})$ & 412,75 & 553,22 & 863,03 & 345,30 & 451,04 & 542,22 & 369,34 & 534,21 & 647,09 & & & \\
\hline$r$ & 0,06 & 0,53 & 0,78 & 0,00 & 0,48 & 0,72 & 0,11 & 0,54 & 0,73 & & & \\
\hline$d$ & 0,36 & 0,59 & 0,79 & 0,39 & 0,66 & 0,80 & 0,37 & 0,63 & 0,78 & & & \\
\hline$\neq Q t$ & $-6793,4$ & $-2334,4$ & 1249,9 & $-2306,4$ & $-894,6$ & 1139,2 & $-620,2$ & 792,3 & 3063,0 & & & \\
\hline
\end{tabular}

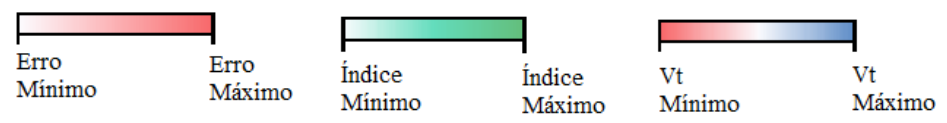

O erro absoluto médio mensal encontrado foi satisfatório com valores baixos e de pouca amplitude entre as bacias. Os piores resultados para este índice foram verificados em Q4 e Q8, as quais possuem em similar dados de ET in situ e S por Sensoriamento Remoto. Ou seja, em termos de quantificação do escoamento, estas fontes combinadas implicam no aumento dos erros. Para uma escala anual, os valores já apresentam uma amplitude maior, chegando a atingir $661 \mathrm{~mm}$ em Q4, no entanto Q5 e Q9 se destacam com menores valores.

Identifica-se uma diferença clara em relação ao coeficiente de correlação, tanto para intervalos mensais como anuais, em que Q5, Q6 e Q7 apresentam valores superiores aos demais, correspondem as equações que não 
possuem dados de S da missão GRACE, o que nos permite concluir que a maioria das imprecisões estão associadas a essa fonte.

A respeito de um padrão entre as bacias, não foi possível identificar uma influência da escala espacial. $\mathrm{O}$ que se observa é que para as menores bacias (B01 e B02) o $\mathrm{r}$ mensal de Q6 ficou bem superior às demais estimativas. Para o cálculo desse escoamento utilizou dados in situ de $\mathrm{S}$ e de $\mathrm{P}$, e agregou dados de SR para ET. Por se tratar de pequenas bacias o uso do SR para estimativa de ET diminuiu a imprecisão desta variável, sendo os dados em terra insuficientes para representação real da bacia.

Os índices de concordância em escala mensal demonstraram o mesmo comportamento que o coeficiente de correlação, em que Q5, Q6 e Q7 se destacam com valores mais altos. Em escala anual, tanto para índice de concordância como para o coeficiente de correlação, Q5 apresenta melhor performance que as demais vazões calculadas, seguido de Q6. Ou seja, para períodos maiores, agregar dados de precipitação por SR traz resultados mais consistentes do que as demais combinações testadas.

O coeficiente Nash-Sutcliffe varia de - $\infty$ a 1. Quanto mais próximo a 1 , mais eficiente é o modelo aplicado, e se menor que zero, significa que a estimativa de vazão pela equação utilizada apresenta erros maiores do que o uso de uma simples média das vazões observadas. Verificou-se que para Q4, Q8, Q9 e Q10 este índice teve uma predominância de valores negativos, com exceção das bacias B04 e B05 com valores positivos. Para Q5 e Q6 todos valores foram positivos, com bacias em que o índice chegou a 0,81 , mostrando a validade da estimativa de escoamento pela equação do balanço hídrico mensal com uso de pelo menos um conjunto de dados de SR.

No que concerne as diferenças da quantificação da altura do escoamento para o período de análise houve uma superestimativa por parte de Q7, seguido de Q6 e Q5. Este fato nos permite aferir que a maior influência na superestimativa dos valores está associada a ET via SR. A vazão calculada Q4 se destaca na subestimativa da altura do escoamento no período, assim como Q8 e Q9. Nesta análise, com um intervalo de tempo longo, evidenciase a influência do efeito de escala, em que B09 e B10, bacias de grandes dimensões, possuem erros reduzidos em comparação as demais.

Além disso, considerando todo o período 2000-2018, o erro de volume escoado é menor com a aplicação de dados de SR, principalmente as vazões calculadas Q9 e Q10. Os erros de volume também diminuem significativamente nas bacias maiores, com desempenhos superiores devido à resolução espacial destes produtos. Ao contrário das demais análises, para um intervalo de tempo longo e uma escala espacial grande, é possível a utilização dos dados de $\mathrm{S}$ da missão GRACE, visto que houve uma redução dos erros para tais estimativas.

Sheffield et al. (2009) usaram estimativas de P, ET e variação do S por SR para calcular o fechamento do balanço de água terrestre para a bacia do Mississippi entre 2003 e 2005 . Concluíram que alcançar o fechamento balanço de água por sensores remotos ainda não era possível, em razão dos grandes desvios na estimativa de $\mathrm{P}$ detectada remotamente e na grande incerteza do $\mathrm{S}$ detectado remotamente. Isso também foi identificado no presente estudo em relação a variação do $\mathrm{S}$ obtido por satélite para intervalos pequenos (mensais e anuais), porém a $\mathrm{P}$ não atuou significativamente neste resultado. No entanto, em um longo período, os valores estimados por SR chegam muito próximos dos valores observados, obtendo uma diferença de apenas 13,67 mm (altura de escoamento) na bacia B05 e 112,95 mm em B07 para Q10 (considerando o período completo de 19 anos), a qual utilizou-se essencialmente dados de SR.

As normais mensais do período de 2000 a 2018 são apresentadas na Figura 5. Evidencia-se a reprodução do padrão sazonal de Q, no entanto, algumas discrepâncias são evidenciadas. Q4 tende a subestimar a vazão, principalmente de julho a dezembro. Q7 superestima os dados durante todo o ano. Q8, Q9 e Q10 ficam abaixo da Q observada de outubro a dezembro. As maiores diferenças para todas as vazões calculadas foram identificadas em agosto. Os meses de melhores estimativas foram fevereiro e março.

\subsection{Armazenamentos de Água Calculados}

A Figura 6 exibe os gráficos de dispersão entre os dados estimados e dados observados do S em escala anual. $\mathrm{O}$ armazenamento $\mathrm{S} 1$ demonstrou ser mais preciso do que S2 e S3, sendo S3 o que apresentou maior dispersão dos dados no entorno da reta ideal, o que está de acordo com o esperado, visto que no cálculo de $\mathrm{S} 3$ foram incorporadas duas variáveis de SR.

A partir das linhas de tendência identificou-se: para $\mathrm{S} 1$ quanto menor os valores de $\mathrm{S}$, melhor a precisão do modelo, ou seja, para valores altos de $\mathrm{S}$, há um aumento nas incertezas; S2 possui um coeficiente angular muito próximo a 1 , isso significa que quando há um aumento dos dados observados, os dados estimados aumentam na mesma proporção, no entanto há um deslocamento da reta o que faz com que os dados apresentem um erro constante nos valores; em S3 nota-se uma maior dispersão dos dados e um aumento no erro absoluto. 


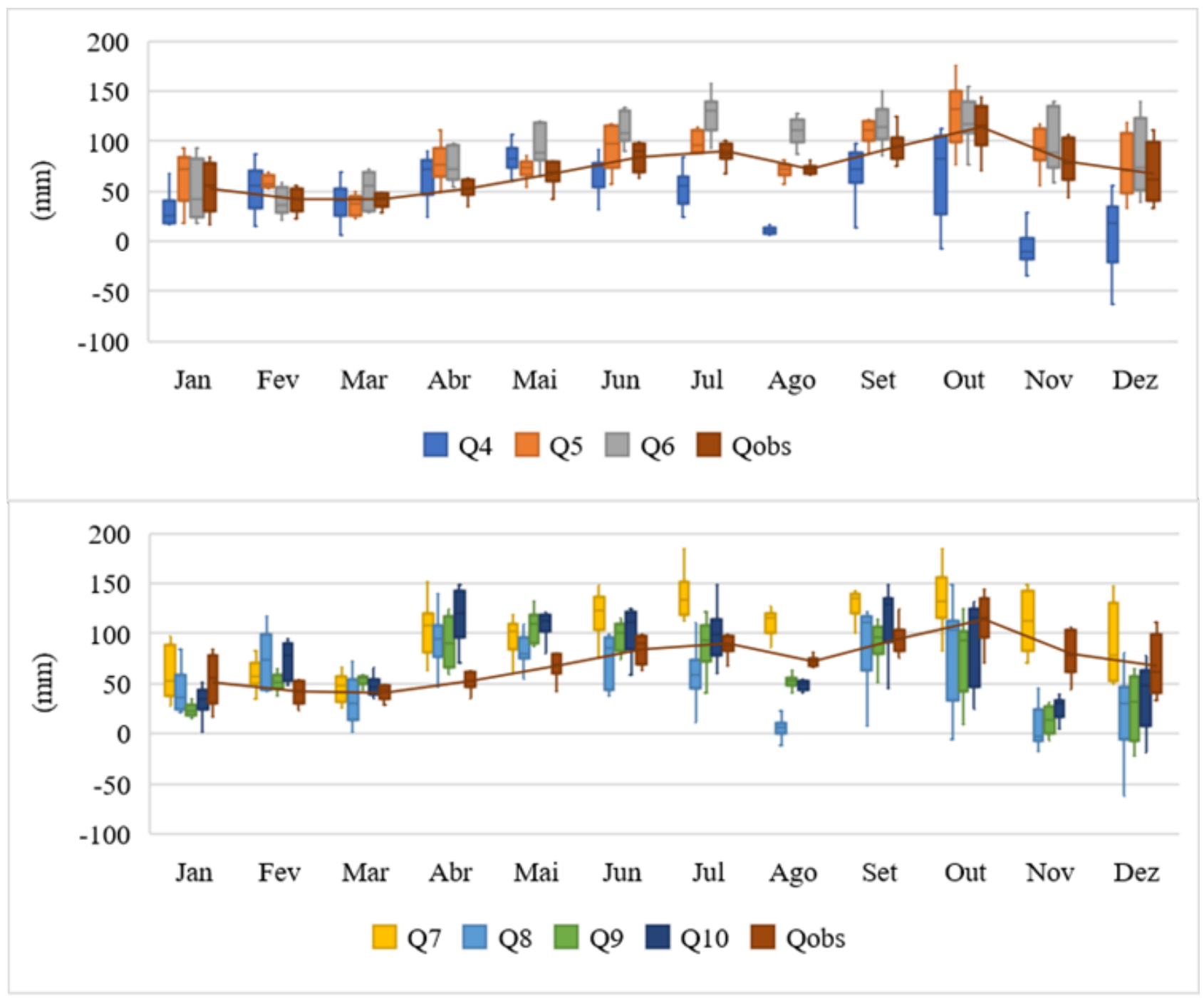

Figura 5 Gráfico de caixas com variação dos valores médios mensais de escoamento (altura) nas bacias, considerando o período de 2000 a 2018, das vazões calculadas pela equação completa do balanço hídrico.

A Tabela 6 demonstra os índices de desempenho para cada $\mathrm{S}$ calculada. Os três modelos apresentaram uma boa predição, em que os índices de concordância e coeficientes de correlação, em geral, apresentaram valores de moderados a bons. Há uma redução destes indicadores em uma escala anual se comparado com os intervalos mensais. O coeficiente Nash-Sutcliffe também teve resultados favoráveis para S1 e S2. Em S3, três das bacias demonstram valores negativos, ou seja, o modelo não foi efetivo na replicação dos dados nestas bacias.

Os erros absolutos médios mensais foram aceitáveis em termos de armazenamento. A performance em relação aos erros apresentou a seguinte relação: $\mathrm{S} 1<\mathrm{S} 2<\mathrm{S} 3$. Além dos menores valores em S1, sua amplitude entre as bacias é bem reduzida em comparação as demais. Como já suposto, a $\mathrm{P}$ via SR tem uma alta precisão nas estimativas para ambas escalas temporais, demonstrando uma boa fonte de dados a ser utilizada no cálculo do balanço hídrico.

Ao analisar os coeficientes de correlação e índices de concordância dos armazenamentos de água terrestre calculados por bacia de estudo, nota-se que em escala mensal S2 demonstrou uma performance levemente superior a $\mathrm{S} 1 \mathrm{em}$ ambos os indicadores, principalmente para pequenas bacias. No entanto, em escala anual, S1 se destacou na maioria das bacias com valores mais altos que S2. O que nos induz à conclusão de que a variável $\mathrm{P}$ por SR tem um bom desempenho tanto mensal como anual, em contraste à ET por SR que tem uma queda de desempenho em escala anual. 


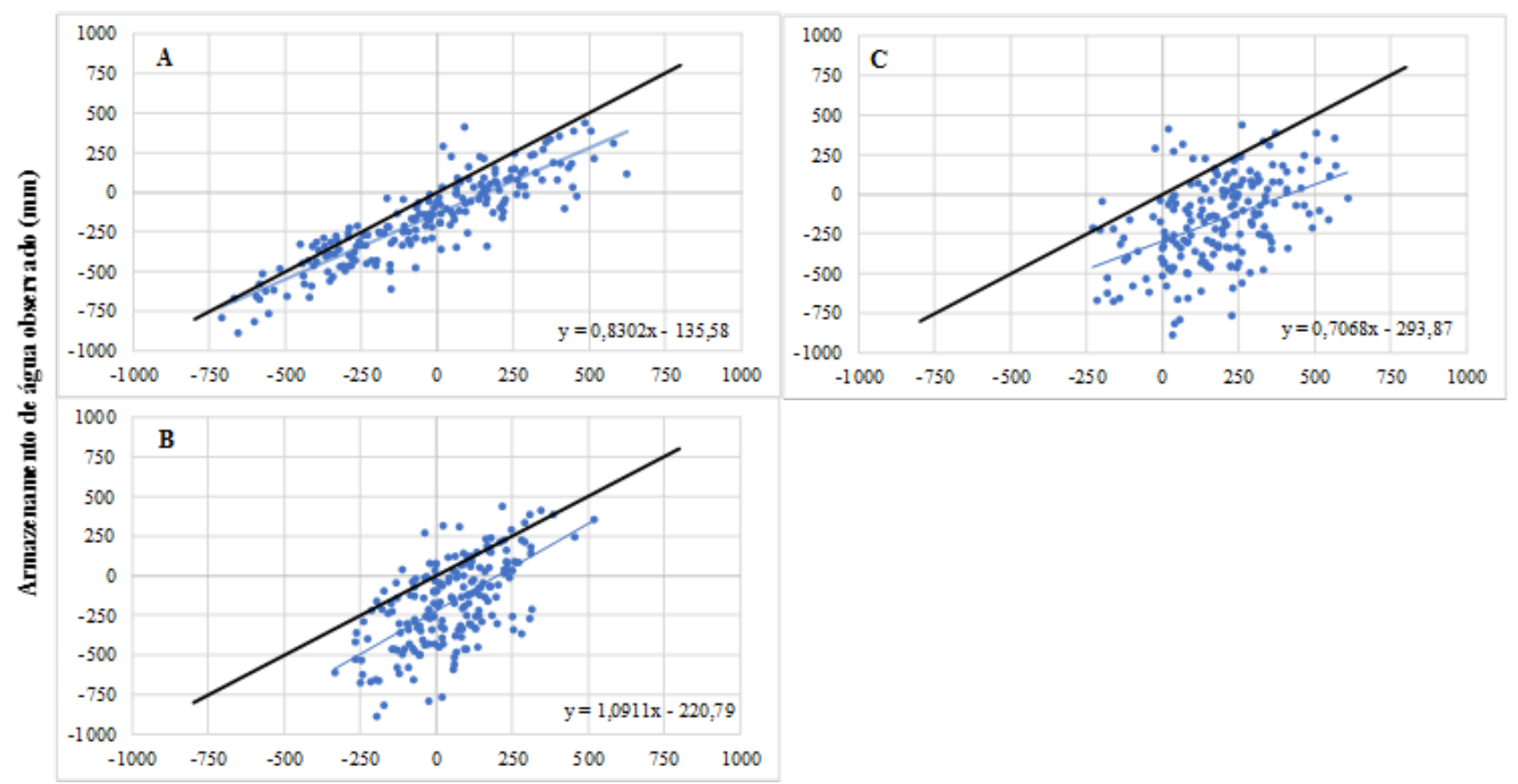

Armazenamento de água calulado (mm)

Figura 6 Gráficos de dispersão do armazenamento anual calculado pela equação completa do balanço hídrico em relação ao observado. A. S1; B. S2; C. S3.

Tabela 6 Análise estatística dos armazenamentos calculados pela equação completa do balanço hídrico, mensal e anual - valores mínimos, médios e máximos, nas bacias analisadas, por índice de desempenho.

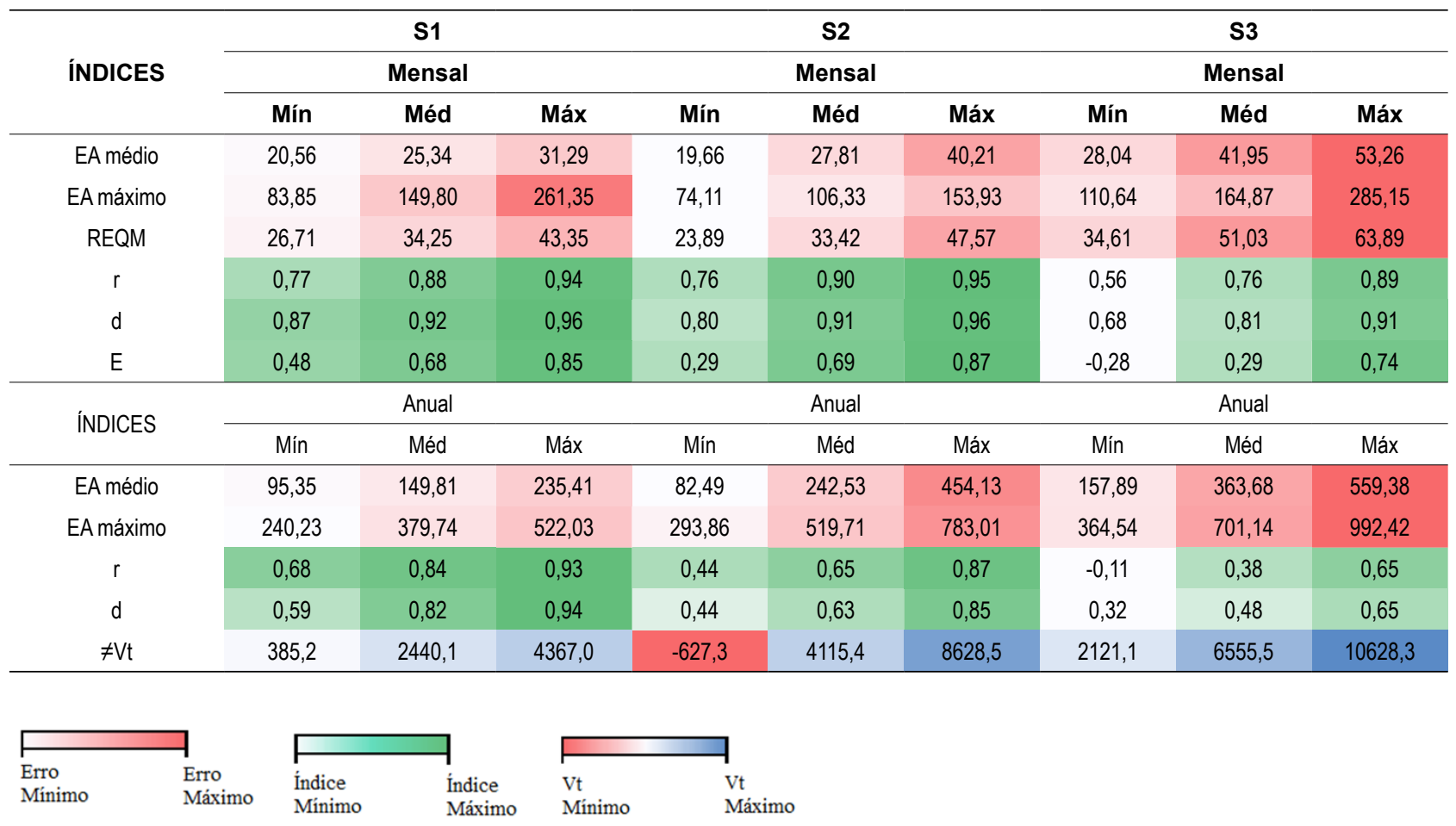


O cenário S3 apresenta performance inferior às demais, porém com menores diferenças em escala mensal. Em escala anual essa diferença é mais acentuada, principalmente a respeito do coeficiente de correlação, apresentando, até mesmo, valores negativos na bacia B05 e B06. Este cenário agrega duas fontes de incerteza, amplificando as discordâncias, sendo que a ET por SR não apresenta bons resultados em escala anual. De maneira geral, os valores entre as bacias não divergiram muito em escala mensal. Anualmente houve uma maior variação, sendo as maiores diferenças entre os produtos nas bacias de tamanhos intermediários.

Os erros absolutos médios mensais e anuais, como já mencionados, são maiores em S3, tanto em escala mensal como anual. $\mathrm{O}$ cenário $\mathrm{S} 1$ tem menores erros em relação às demais estimativas de $\mathrm{S}$ em escala anual. Se destaca a bacia B03 com maiores erros, seguido de B02 que são bacias relativamente pequenas. Com valores mais baixos de erros anuais para os três modelos ficaram as maiores bacias, B09 e B10, evidenciando-se um efeito de escala.

Condizente com os maiores erros, S3 possui as maiores diferenças do somatório total dos armazenamentos de água. Outro ponto de destaque é que as três estimativas apresentam uma tendência, em longo prazo, de superestimativa dos valores, em que apenas S2 apresentou valores negativos para duas bacias. É evidente a redução das diferenças em S2 e S3 nas bacias de maiores dimensões
(B09 e B10). O mesmo não é observado em S1, logo, o efeito escala age sobre a ET obtida por satélite.

Outro dado importante de se analisar é o saldo de armazenamento total no período de análise (2000 - 2018), por bacia, como mostra a Figura 7. Para a maioria das bacias, os valores mais baixos e negativos de $\mathrm{S}$ foram identificados em S0 (armazenamento de referência), o qual foi obtido apenas com uso de dados in situ. Esta evidência nos permite inferir uma certa imprecisão associada a esta fonte de dados, visto que se espera que valores históricos de S se aproximem de zero, quando se trata de bacias hidrográficas em equilíbrio hídrico, caso contrário, as bacias em questões estariam enfrentando um longo período de déficit hídrico.

O modelo com melhores resultados foi S2, o qual se utilizou dados de ET advindos de SR. Isto nos induz a afirmar que agregar dados de SR no cálculo de S para um intervalo de tempo grande pode aumentar a acurácia da predição desta variável.

A respeito do padrão sazonal do $\mathrm{S}$ e possíveis períodos mais tendenciosos, calculou-se a normal mensal para o período de 2000 a 2018, Figura 8. Em geral todas estimativas de $\mathrm{S}$ representaram o comportamento sazonal desta variável muito bem, $\mathrm{S} 1$ foi o que se destacou com maior similaridade com os dados observados. S2 e S3 apresentam maior superestimativa entre abril e setembro, $\mathrm{o}$ que possivelmente está atrelado as limitações da ET via SR. Os três modelos tiveram maior precisão de janeiro a março.

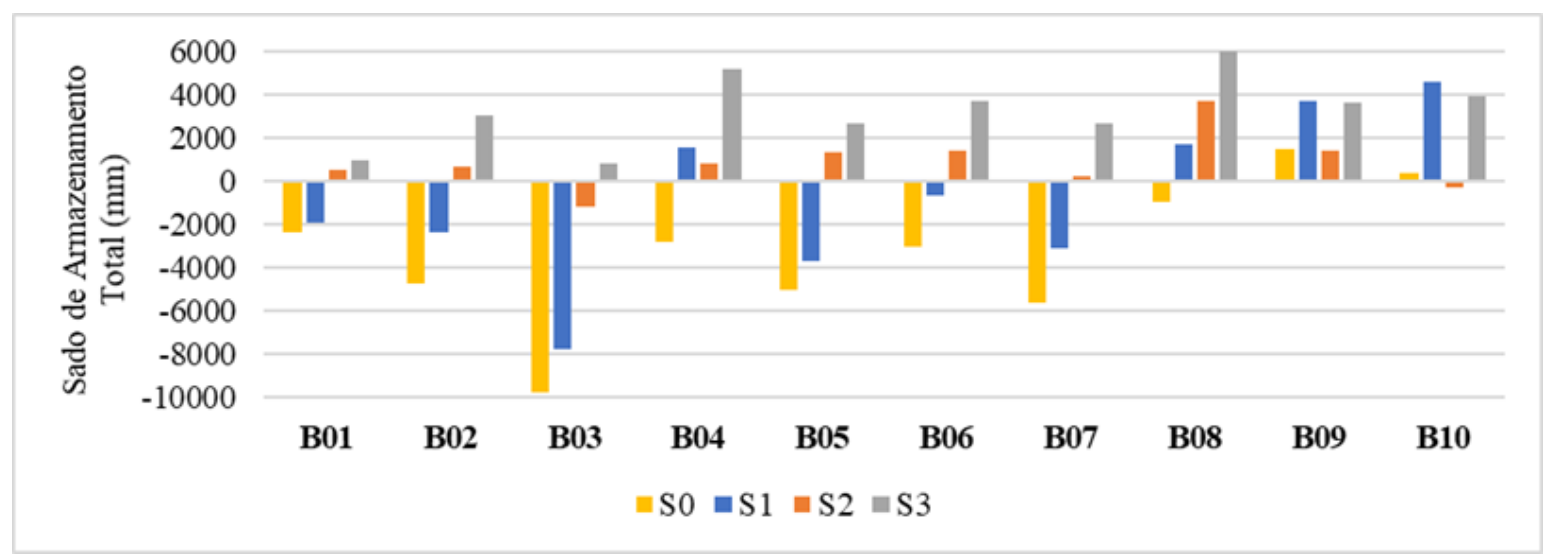

Figura 7 Saldo de armazenamento no período 2000-2018 por bacia. 


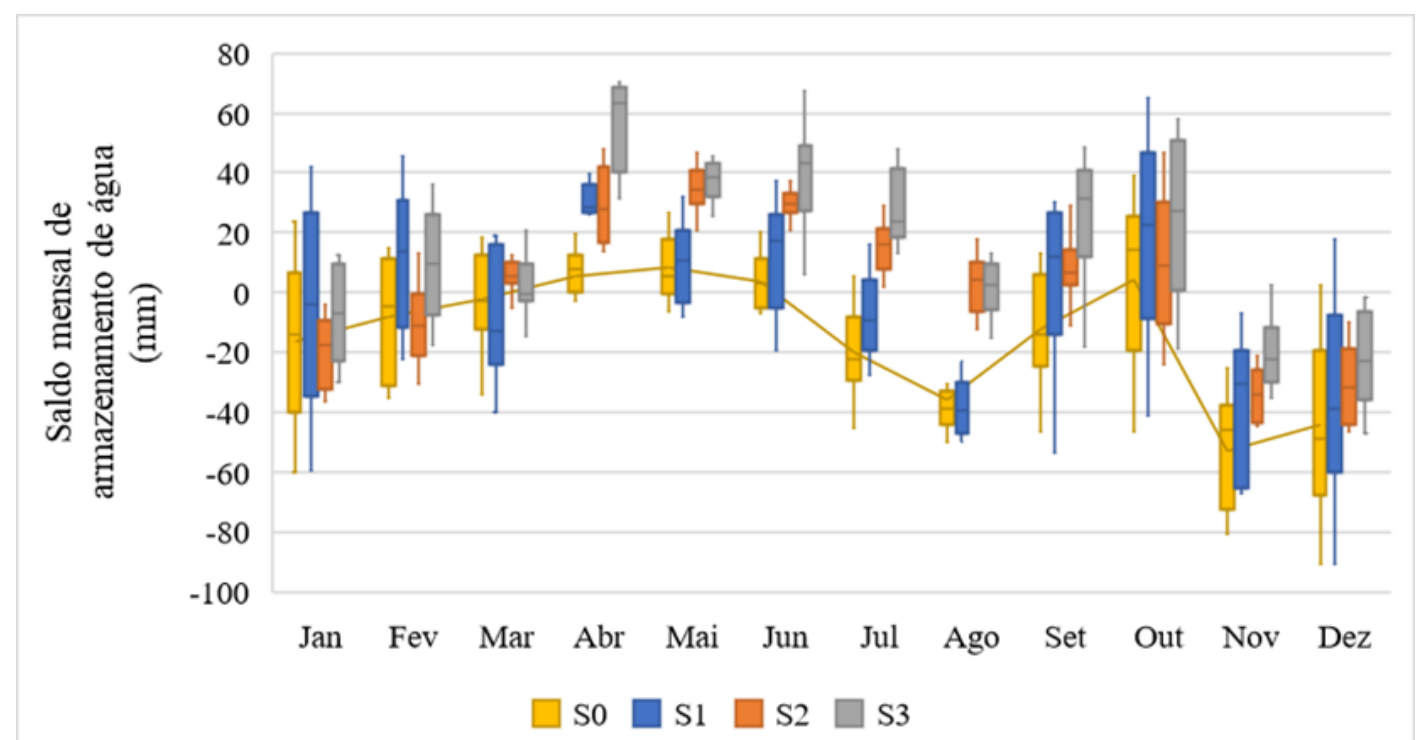

Figura 8 Gráfico de caixas com variação dos valores médios mensais de armazenamento de água (altura) nas bacias, considerando o período de 2000 a 2018.

\section{Conclusões}

Neste trabalho foi possível identificar as maiores fontes de incertezas no cálculo do balanço hídrico integrando dados in situ e observados por satélite, além de verificar os efeitos de escala espacial em diferentes intervalos de tempo.

Ao aplicar a equação reduzida do balanço hídrico, para as quatro estimativas, obteve-se um ótimo desempenho dos índices. Não foi verificado um efeito de escala espacial. A tendência da diferença histórica é ditada pela ET, quando se utilizou a ET in situ houve uma subestimativa dos valores, e quando se utilizou ET via SR superestimou a Q. Q2 apresentou melhor performance, o que indica que a utilização de ET via SR é uma alternativa viável quando há escassez destes dados em campo. Em geral, todas estimativas foram capazes de reproduzir o padrão comportamental da $\mathrm{Q}$, porém recomendaríamos na seguinte ordem: Q2 $>\mathrm{Q} 3>\mathrm{Q} 0>\mathrm{Q} 1$, considerando a situação de disponibilidade de dados de campo do trabalho atual.

Ao obter o balanço hídrico pela equação completa, evidenciou-se que a menor fonte de incertezas proveniente de SR em uma escala anual foi a P, seguido da ET e da combinação de ambas, por último o $\mathrm{S}$. As equações que utilizaram dados de SR na estimativa do S não foram capazes de quantificar e representar o comportamento de $Q$ de forma satisfatória. No entanto, a respeito das diferenças do somatório das vazões no período histórico, a aplicação de dados de SR de S se torna uma alternativa melhor do que o uso de dados in situ, em que os erros diminuem significativamente, principalmente nas maiores bacias. Logo sugerimos o uso dos cenários na seguinte ordem:
Q5 $>$ Q6 $>$ Q7, tanto em escala mensal quanto anual, não sendo recomendado os demais modelos para predição de $\mathrm{Q}$.

Ao estimar o $\mathrm{S}$, os três modelos apresentaram uma boa predição, os índices de concordância e coeficientes de correlação demonstraram valores de moderados a bons, sendo superiores em escala mensal em relação a anual. Em geral, todas as estimativas de $\mathrm{S}$ representaram o comportamento sazonal desta variável muito bem, em que $\mathrm{S} 1$ foi o que se destacou com maior similaridade com os dados observados, a qual utilizava dados de P via SR, sendo a variável com menor imprecisão; desta forma, elencamos do melhor ao pior desempenho: $\mathrm{S} 1>\mathrm{S} 2>\mathrm{S} 3$.

A metodologia aplicada no presente trabalho pode ser replicada em diversas localidades do globo, em razão da alta disponibilidade dos dados de sensoriamento remoto. Como possíveis desdobramentos da presente pesquisa, sugere-se analisar esses dados em áreas com diferentes características físicas e climatológicas e a interferência na sua acurácia. Existem também diversos outros produtos de SR, elaborados a partir de diferentes algoritmos, com estimativa espaço-temporal de componentes do ciclo hidrológico que podem ser utilizados ou agregados, não se limitando apenas aos que foram escolhidos nesta pesquisa.

\section{Referências}

Bastiaanssen, W.G.M. \& Chandrapala, L. 2003.Water balance variability across Sri Lanka for assessing agricultural and environmental water use. Agricultural water management, 58(2): 171-192.

D’Angiolella, G.; Vasconcellos, V.L.D. \& Rosa, J.W.C. 2005. Estimativa e espacialização do balanço hídrico na 
mesorregião sul da Bahia. In: SIMPÓSIO BRASILEIRO DE SENSORIAMENTO REMOTO, Goiânia, INPE, p. 83-90.

Gao, H.; Tang, Q.; Ferguson, C.R.; Wood, E.F. \& Lettenmaier, D.P. 2010. Estimating the water budget of major US river basins via remote sensing. International Journal of Remote Sensing, 31(14): 3955-3978.

Martens, B.; Miralles, D.; Lievens, H.; Van Der Schalie, R.; De Jeu, R.A.; Fernández-Prieto, D.; Beck, H.; Dorigo, W. \& Verhoest, N. 2017. GLEAM v3: Satellite-based land evaporation and root-zone soil moisture. Geoscientific Model Development, 10(5): 1903-1925.

McCabe, M.F.; Wood, E.F.; Wójcik, R.; Pan, M.; Sheffield, J.; Gao, H. \& Su, H. 2008. Hydrological consistency using multi-sensor remote sensing data for water and energy cycle studies. Remote Sensing of Environment, 112(2): 430-444.

Moreira, A.A.; Fassoni-Andrade, A.C.; Ruhoff, A.L. \& de Paiva, R.C.D. 2018. Balanço hídrico no Pantanal: uma abordagem por Sensoriamento Remoto. In: $7^{\circ} \mathrm{SIMPÓSIO}$ DE GEOTECNOLOGIAS NO PANTANAL, Jardim, MS, 2018. Jardim, Embrapa Informática Agropecuária/INPE, p. 695-704.

Moreira, A.A. \& Ruhoff, A.L. 2017. Análise do balanço hídrico na América do Sul por Sensoriamento Remoto. In: SIMPÓSIO BRASILEIRO DE RECURSOS HÍDRICOS, 22, Florianópolis, 2017. Recursos Eletrônicos, Porto Alegre, ABRH, p. 01-08.

Paiva, R.C.D.D. \& Ruhoff, A.L. 2017. Desafios na estimativa do ciclo hidrológico terrestre por Sensoriamento Remoto. In: SIMPÓSIO BRASILEIRO DE RECURSOS HÍDRICOS, 22, Florianópolis, 2017. Recursos Eletrônicos, Porto Alegre, ABRH, p. 01-08.

Pan, M.; Sahoo, A.K.; Troy, T.J.; Vinukollu, R.K.; Sheffield, J. \& Wood, E.F. 2012. Multisource estimation of long-term terrestrial water budget for major global river basins. Journal of Climate, 25(9): 3191-3206.

Porto, K.G. \& Ferreira, I.M. 2012. Gestão das bacias hidrográficas urbanas e a importância dos ambientes ciliares. Geografia em Questão, 5(2): 43-57.

Sentelhas, P.C.; Pereira, A.R.; Marin, F.R.; Angelocci, L.R.; Alfonsi, R.R.; Caramori, P.H.; \& Swart, S. 1999. BHBRASIL: balanços hídricos climatológicos de 500 localidades brasileiras. Piracicaba, ESALQ/USP.

Sheffield, J.; Ferguson, C.R.; Troy, T.J.; Wood, E.F. \& McCabe, M.F. 2009. Closing the terrestrial water budget from satellite remote sensing. Geophysical Research Letters, 36(7).

Soares, P.A.; Pinheiro, A.; Soares, K.H. \& Zucco, E. 2010. Estimativa da disponibilidade hídrica em pequenas bacias hidrográficas com escassez de dados fluviométricos. Revista de estudos ambientais, 12(1): 29-38.

Tang, Q.; Gao, H.; Yeh, P.; Oki, T.; Su, F. \& Lettenmaier, D. P. 2010. Dynamics of terrestrial water storage change from satellite and surface observations and modeling. Journal of Hydrometeorology, 11(1): 156-170.

Thomas, A.C.; Reager, J.T.; Famiglietti, J.S. \& Rodell, M. 2014. A GRACE-based water storage deficit approach for hydrological drought characterization. Geophysical Research Letters, 41(5): 1537-1545.

Troch, P.; Durcik, M.; Seneviratne, S.; Hirschi, M.; Teuling, A.; Hurkmans, R. \& Hasan, S. 2007. New data sets to estimate terrestrial water storage change. Eos, Transactions American Geophysical Union, 88(45): 469-470.

Tropical Rainfall Measuring Mission (TRMM). 2011. TRMM (TMPA/3B43) Rainfall Estimate L3 1 month 0.25 degree $\mathrm{x}$ 0.25 degree V7, Greenbelt, MD, Goddard Earth Sciences Data and Information Services Center (GES DISC). Disponível em: <https://disc.gsfc.nasa.gov/datasets/TRMM_3B43_7/ summary>. Acesso em: Set. 2019. 